\title{
Introduction to this special issue - "Autophagy and Cancer: current biology and drug development"
}

\author{
Chun Hei Antonio Cheung ${ }^{1,2}$ \\ 'Department of Pharmacology, College of Medicine, National Cheng Kung University, Tainan 70101, Taiwan. \\ ${ }^{2}$ Institute of Basic Medical Sciences, College of Medicine, National Cheng Kung University, Tainan 70101, Taiwan.
}

Correspondence to: Prof. Chun Hei Antonio Cheung, College of Medicine, National Cheng Kung University, Tainan 70101, Taiwan. E-mail: acheung@mail.ncku.edu.tw

How to cite this article: Cheung CHA. Introduction to this special issue - "Autophagy and Cancer: current biology and drug development". J Cancer Metastasis Treat 2019;5:60. http://dx.doi.org/10.20517/2394-4722.2018.74

Received: 14 Nov 2018 First Decision: 28 Nov 2018 Revised: 5 Dec 2018 Accepted: 10 Dec 2018 Published: 9 Aug 2019

Science Editor: Chun Hei Antonio Cheung Copy Editor: Jia-Jia Meng Production Editor: Tian Zhang

It is my pleasure, as one of the editorial board members, to introduce the readers of JCMT to this special issue entitled "Autophagy and Cancer: current biology and drug development".

Autophagy is a fundamental process for cells to degrade unwanted proteins/damaged organelles and also to recycle cellular components. Since its discovery on 1960's, a vast amount of effort has been made in understanding the physiological role/s of this process. For example, it is now known that mitosis, apoptosis, and autophagy are inter-connected and inter-regulated in cells ${ }^{[1]}$. It is also known that upregulation of autophagy is a double-edged sword that promotes both cell survival and cell death, depending on the circumstances. However, the pathological role/s of autophagy in normal-to-cancer cell transformation, tumor development, and tumor drug resistance was not clear until the arrival of various breakthrough discoveries in the past 15 years. Noticeably, it has been demonstrated that dysregulation of autophagy (and probably downregulation) induces genomic instability in non-cancerous cells and subsequently promotes tumorigenesis $^{[2]}$. In contrast, upregulation of autophagy has been shown to enhance the survival ability of cancer cells in response to various micro-environmental stresses and different chemotherapeutic agents $^{[3]}$. Therefore, autophagy is currently a "hot" cellular pathway target for the development of cancer therapeutics ${ }^{[4-7]}$.

This special issue contains reviews focusing on recent understandings on the regulation of autophagy in non-cancerous cells and dysregulation of this process in cancer cells. Reviews on recent advances in the development of autophagy modulators for cancer treatment are also included in this special issue.

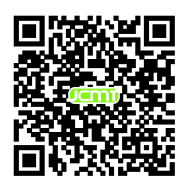




\section{DECLARATIONS}

\section{Authors' contributions}

Manuscript drafting: Cheung CHA.

\section{Availability of data and materials}

Not applicable.

\section{Financial support and sponsorship}

None.

\section{Conflicts of interest}

All authors declared that there are no conflicts of interest.

\section{Ethical approval and consent to participate}

Not applicable.

\section{Consent for publication}

Not applicable.

\section{Copyright}

(c) The Author(s) 2019.

\section{REFERENCES}

1. Thorburn A. Apoptosis and autophagy: regulatory connections between two supposedly different processes. Apoptosis 2008;13:1-9.

2. Brech A, Ahlquist T, Lothe RA, Stenmark H. Autophagy in tumour suppression and promotion. Mol Oncol 2009;3:366-75.

3. Prieto-Domínguez N, Ordóñez R, Fernández A, García-Palomo A, Muntané J, et al. Modulation of Autophagy by Sorafenib: Effects on Treatment Response. Front Pharmacol 2016;7:151.

4. Duffy A, Le J, Sausville E, Emadi A. Autophagy modulation: a target for cancer treatment development. Cancer Chemother Pharmacol 2015;75:439-47.

5. Janji B, Berchem G, Chouaib S. Targeting Autophagy in the Tumor Microenvironment: New Challenges and Opportunities for Regulating Tumor Immunity. Front Immunol 2018;9:887.

6. Lee JYC, Kuo CW, Tsai SL, Cheng SM, Chen SH, et al. Inhibition of HDAC3- and HDAC6-Promoted Survivin Expression Plays an Important Role in SAHA-Induced Autophagy and Viability Reduction in Breast Cancer Cells. Front Pharmacol $2016 ; 7: 81$.

7. Kaliszczak M, van Hechanova E, Li Y, Alsadah H, Parzych K, et al. The HDAC6 inhibitor C1A modulates autophagy substrates in diverse cancer cells and induces cell death. Br J Cancer 2018;119:1278-87. 